\begin{tabular}{|c|c|c|}
\hline $\begin{array}{l}\text { OPEN ACCESS } \\
\text { Vol. 2 No. 2:1-9 } \\
\text { Thanun 2019 } \\
\text { Artikel penelitian 圈 }\end{array}$ & $\begin{array}{c}\text { Jurreal Aliwatilklestari } \\
\text { E-ISSN: 2598-8204 } \\
\text { http://ojs.umrah.ac.id/index.php/akuatiklestari } \\
\text { Dol : https://doi.org/10.31629/akuatiklestari.v2i2.984 }\end{array}$ & $a=$ \\
\hline
\end{tabular}

\title{
Identifikasi Ikan Lokal di Tempat Pendaratan Ikan dan Pola Pemanfaatan Perikanan di Pulau Alai
}

\author{
Identification of Local Fish at Fishing port and the use of Fishery Term on Alai Island
}

\section{Nurul Hidayah Eka Fitri ${ }^{1}$, Febrianti Lestari'1, Fitria Ulfah ${ }^{2}$}

${ }^{1}$ Manajemen Sumberdaya Perairan, Fakultas Ilmu Kelautan dan Perikanan, Universitas Maritim Raja Ali Haji, Tanjungpinang, Indonesia 29111

2 Sosial Ekonomi Perikanan, Fakultas Ilmu Kelautan dan Perikanan, Universitas Maritim Raja Ali Haji, Tanjungpinang, Indonesia 29111

\section{$\square$ Info Artikel:}

Diterima: 29 Januari 2019

Revisi: 13 Februari 2019

Disetujui: 27 April 2019

Dipublikasi: 30 Mei 2019

\section{Keyword:}

Ikan Lokal, Pola Pemanfaatan, Perikanan,

Identifikasi, Pulau Alai

\author{
$\triangle$ Penulis Korespondensi: \\ Nurul Hidayah Eka Fitri \\ Manajemen Sumberdaya Perairan, \\ Fakultas IImu Kelautan dan Perikanan, \\ Universitas Maritim Raja Ali Haji \\ Email: nurulhidayah1616@gmail.com
}

\begin{abstract}
ABSTRAK. Penelitian mengenai identifikasi jenis ikan lokal dan pola pemanfaatan perikanan telah dilakukan di Pulau Alai, Kecamatan Ungar, Kabupaten Karimun. Tujuan penelitian ini adalah untuk mengetahui jenis - jenis ikan lokal dan pola pemanfaatan perikanan di Pulau Alai. Penelitian ini dilakukan dengan metode purposive sampling pada 2 tempat pendaratan ikan, yang juga dijadikan nelayan setempat sebagai tempat melabuhkan perahu. Komposisi hasil tangkapan ikan lokal yang didapat sebanyak 7 jenis. Hasil tangkapan utama terdapat 4 jenis ikan, yaitu ikan lome (Harpodon nehereus), ikan bulu ayam (Coilia sp.), ikan biang (Setipinna sp.), dan ikan timah (Trichiurus sp.). Sedangkan hasil tangkapan sampingan terdapat 3 jenis ikan, yaitu ikan Diles atau ikan Gelik (Otolithoides sp.), ikan baji - baji (Grammoplites scaber), dan ikan sebelah (Cynoglossus sp.). Persentase tertinggi di tempat pendaratan ikan I dan II adalah ikan lome yang merupakan ikan hasil tangkapan utama sebesar 38-39\%. Sedangkan persentase terendah di tempat pendaratan ikan I dan II adalah ikan baji - baji sebesar 2\%. Pola pemanfaatan perikanan di Pulau Alai masih cenderung sederhana dan tradisional. Alat tangkap jaring di Pulau Alai tidak memiliki nilai selektivitas yang tinggi.
\end{abstract}

ABSTRACT. Research on the identification of local fish species and fishery utilization patterns has been carried out on Alai Island, Ungar District, Karimun Regency. The purpose of this study was to determine the types of local fish and fishery utilization patterns on Alai Island. This research was conducted with a purposive sampling method at 2 fish landing locations, which are also used as local fishermen as a boat berth. The composition of local fish catches obtained as many as 7 types. The main catch is 4 species of fish, namely lome fish (Harpodon nehereus), spines (Coilia sp.), Prickly fish (Setipinna sp.), And lead fish (Trichiurus sp.). Whereas bycatch there are 3 types of fish, namely Diles or Gelik fish (Otolithoides sp.), Wedge fish (Grammoplites scaber), and adjoining fish (Cynoglossus sp.). The highest percentage at the landing sites of fish I and II are lome fish which is the main catch fish by $38-39 \%$. While the lowest percentage at fish landing sites I and II was $2 \%$ fish hedging. The pattern of fishery utilization on Alai Island still tends to be simple and traditional. Clean fishing gear on Alai Island does not have a high selectivity value.

筫 How to cite this article:

Fitri, N.H.E., Lestari, F., \& Ulfah, F. (2019). Identifikasi Ikan Lokal di Tempat Pendaratan Ikan dan Pola Pemanfaatan Perikanan di Pulau Alai. Jurnal Akuatiklestari, 2(2): 1-9. https://doi.org/10.31629/akuatiklestari.v2i2.984

\section{PENDAHULUAN}

Pulau Alai merupakan salah satu Pulau yang terletak di Kabupaten Karimun Kepulauan Riau. Pulau Alai memiliki luas wilayah sebesar $102 \mathrm{~km}^{2}$, yang terdiri dari satu Kelurahan dan tiga Desa. Kelurahan Alai memiliki wilayah terluas yaitu sebesar $45 \mathrm{~km}^{2}$ dan Desa Ngal dengan luas yang terkecil sebesar $15 \mathrm{~km}^{2}$ (BPS, 2015). Pulau Alai dikelilingi laut dan sebagian masyarakatnya mendiami wilayah pesisir. Masyarakat Pulau Alai sebagian berprofesi sebagai nelayan, dengan mayoritas armada penangkapan berupa perahu (sampan) dan beberapa menggunakan kapal. Perahu (sampan) lebih sederhana tanpa mesin dan hanya menggunakan dayung, sedangkan kapal sudah menggunakan mesin.

Alat tangkap yang dominan digunakan oleh nelayan masih sederhana yaitu alat tangkap jaring. Jaring pengoperasiannya ditebar di daerah penangkapan dengan tiang tancap dan diberi pelampung pada pinggir jaring (Susiana \& Rochmady, 2018). Berdasarkan survei, alat tangkap jaring yang digunakan nelayan Pulau Alai cenderung tidak selektif. Alat tangkap yang tidak selektif dapat menangkap ikan atau organisme yang bukan sasaran 
penangkapan (non target). Dengan alat tangkap yang tidak selektif, hasil tangkapan yang terbuang akan meningkat, karena banyaknya jenis ikan non target yang turut tertangkap.

Berdasarkan hasil survei sementara, sumberdaya ikan di perairan Pulau Alai sangat beragam dan melimpah. Selama ini, potensi sumberdaya perikanan di perairan Pulau Alai telah dimanfaatkan oleh masyarakat sebagai sumber mata pencaharian untuk menunjang perekonomian. Beberapa jenis ikan yang terdapat di perairan Pulau Alai adalah ikan lome, ikan langgai, ikan biang, dan ikan bulu ayam. Pada umumnya, jenis ikan yang terdapat di perairan Pulau Alai merupakan jenis ikan yang jarang dijumpai dan didapatkan di daerah lain. Hal ini menyebabkan permintaan terhadap sumberdaya ikan tersebut terjadi secara terus menerus, baik oleh masyarakat lokal maupun non lokal.

Kelimpahan jenis - jenis ikan di perairan Pulau Alai belum pernah teridentifikasi, sehingga perlu dilakukan identifikasi jenis ikan lokal yang didaratkan di tempat pendaratan ikan Pulau Alai. Identifikasi jenis ikan lokal dilakukan agar tersedia data jenis - jenis ikan lokal yang pernah ada di perairan Pulau Alai yang dikhawatirkan tidak pernah teridentifikasi apabila salah satu jenis ikan tersebut punah. Selain melakukan identifikasi, juga dilakukan penelitian untuk mengetahui pola pemanfaatan sumber daya perikanan, yang mencakup jenis ikan yang ditangkap, ukuran ikan hasil tangkapan, komposisi hasil tangkapan, jenis alat tangkap, kapal yang digunakan dalam kegiatan penangkapan, fishing ground, musim penangkapan dan pengolahan hasil tangkapan. Data dan informasi mengenai jenis ikan lokal dan kajian pola pemanfaatan sumberdaya perikanan dapat dijadikan sebagai dasar atau acuan pengelolaan dan pelestarian serta kebijakan pemanfaatan sumberdaya perikanan yang berkelanjutan dimasa yang akan datang.

\section{BAHAN DAN METODE}

\subsection{Waktu dan tempat}

Penelitian ini dilaksanakan pada Bulan Mei sampai dengan Bulan Juni 2018 yang berlokasi di Pulau Alai Kecamatan Ungar Kabupaten Karimun Provinsi Kepulauan Riau. Peta lokasi dapat dilihat pada Gambar 1.

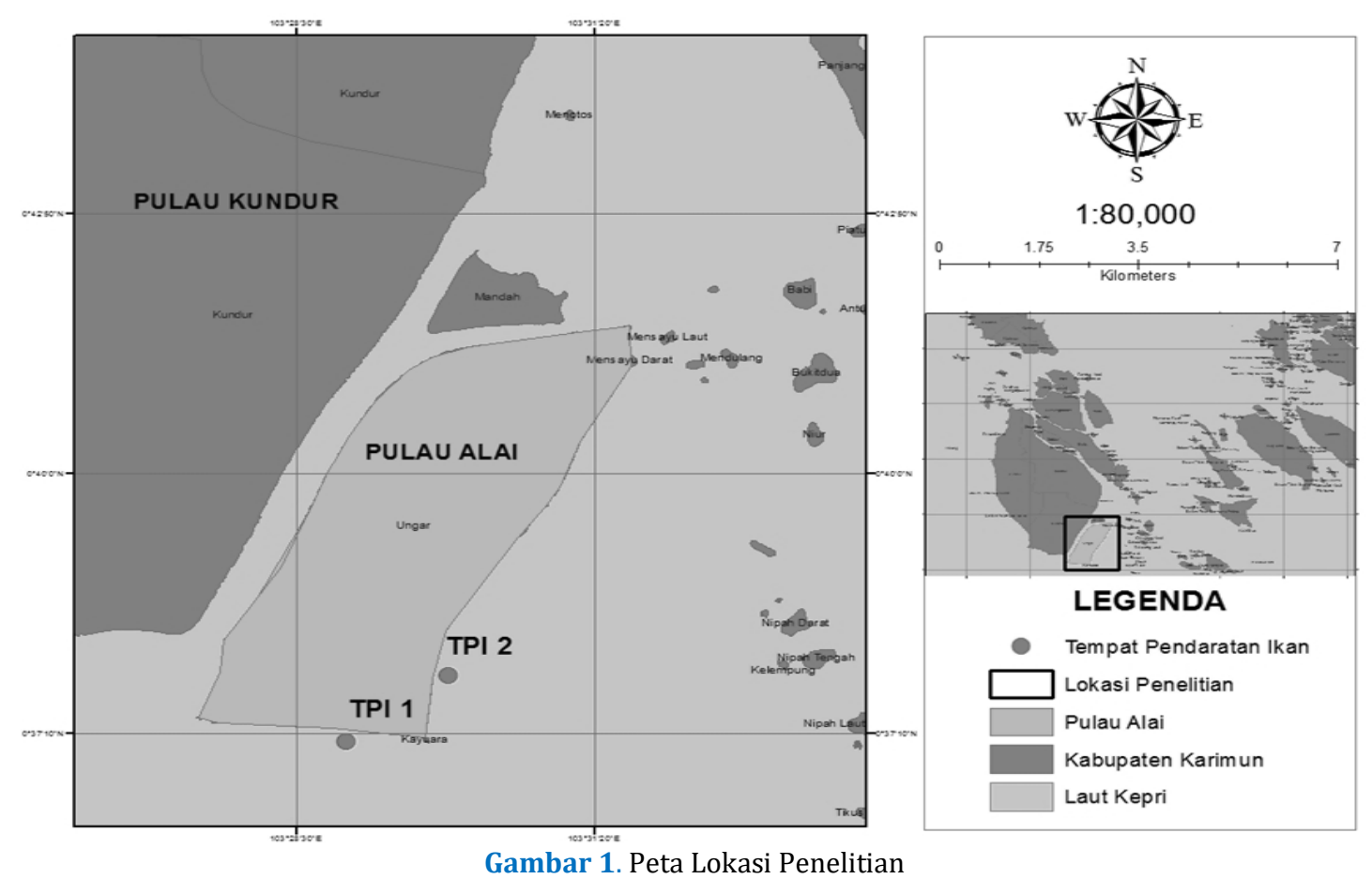

\subsection{Alat dan bahan}

Peralatan yang digunakan dalam penelitian terdiri dari: kamera yang digunakan untuk mengambil dokumentasi objek penelitian, alat tulis dan lembar kerja untuk mencatat hasil tangkapan dan wawancara, lembar kuisioner untuk wawancara pola pemanfaatan perikanan, penggaris untuk mengukur panjang ikan hasil tangkapan, timbangan untuk penimbangan hasil tangkapan ikan, dan sampel ikan sebagai objek penelitian.

\subsection{Prosedur penelitian}

Tahapan penelitian terdiri dari penentuan lokasi penelitian, penentuan responden, pengambilan data, serta pengolahan dan analisis data. Penelitian dilakukan melalui survei lapang. Penentuan lokasi penelitian dilakukan menggunakan metode purposive sampling. Terdapat dua lokasi penelitian, yaitu tempat pendaratan ikan Batu Limau dan tempat pendaratan ikan Batu Beliang. Lokasi penelitian merupakan tempat nelayan mendaratkan ikan dan melabuhkan perahu penangkapan ikan. Penentuan responden menggunakan rumus slovin (Rahman et al., 2016), sehingga didapatkan total responden sebanyak 36 orang. Pembagian jumlah responden di tempat pendaratan ikan I dan II dapat dilihat pada Tabel 1 . 
Tabel 1. Jumlah Responden Penelitian

\begin{tabular}{ccccc} 
No & Tempat Pendaratan Ikan & Jumlah nelayan (N) & Standar Estimasi (e) & Hasil (n) \\
$\mathbf{1}$ & I & 150 orang & $20 \%$ & 21 orang \\
$\mathbf{2}$ & II & 15 orang & - & 15 orang \\
& Total & & & 36 orang \\
\hline
\end{tabular}

\subsection{Teknik pengambilan data}

Data yang dikumpulkan berupa data primer yang dilakukan dengan cara mewawancarai nelayan menggunakan lembar kuisioner. Informasi yang diperoleh dari hasil wawancara berupa data kegiatan perikanan dan pola pemanfaatannya. Selain wawancara, dilakukan pengamatan langsung (observasi) ke tempat pendaratan ikan untuk mendapatkan data ikan berupa foto yang digunakan untuk identifikasi jenis ikan di Pulau Alai Kecamatan Ungar.

Pengumpulan data sekunder dilakukan dengan mengumpulkan data dari intansi terkait seperti kantor camat Pulau Alai mengenai data monografi Desa atau Dinas Kelautan dan Perikanan Kabupaten Karimun untuk mendapatkan data perikanan terkait penelitian.

\subsection{Pengolahan dan Analisis Data}

\section{Identifikasi Jenis Ikan Lokal}

Spesies ikan yang diperoleh dari lapangan akan diidentifikasi secara morfologi berdasarkan kesamaan ciri. Identifikasi ikan menggunakan buku Taksonomi dan Kunci Identifikasi Ikan dari Hasanuddin Saanin tahun 1968 dan buku Jenis - Jenis Ikan di Indonesia dari ACIAR (Australian Centre for International Agricultural Research).

\section{Komposisi Hasil Tangkapan}

Komposisi hasil tangkapan ikan dihitung dengan menggunakan rumus :

$$
P=\frac{n i}{N} \times 100 \%
$$

Keterangan:

$\mathrm{P}=$ Persentasi jenis ikan yang tertangkap (\%)

$\mathrm{ni}=$ Jumlah Individu Ikan $(\mathrm{kg})$

$\mathrm{N}=$ Jumlah Total $(\mathrm{kg})$

\section{Selektivitas Alat Tangkap}

Metode analisis data yang dilakukan sesuai dengan kriteria pembobotan alat tangkap ramah lingkungan yang dikeluarkan oleh Departemen Kelautan dan Perikanan tahun 2006. Food Agriculture Organization (FAO), sebuah lembaga di bawah naungan Perserikatan Bangsa Bangsa yang menangani masalah pangan dan pertanian dunia), pada tahun 1995 mengeluarkan suatu tata cara bagi kegiatan penangkapan ikan yang bertanggung jawab (Code of Conduct for Resposible Fisheries - CCRF). Dalam CCRF ini, FAO menetapkan serangkaian kriteria bagi teknologi penangkapan ikan ramah lingkungan. Pembobotan kriteria alat tangkap ramah lingkungan dapat dilihat pada Tabel 2.

Setelah skor atau nilai didapat, untuk menentukan hasil akhirnya diperoleh dengan cara membagi jumlah total bobot nilai dengan total responden, atau digunakan rumus ketetapan sebagai berikut (Sima et al., 2013).

$$
\begin{aligned}
& \sum X=\frac{\sum X_{1}+X_{2}+\cdots \ldots \ldots X_{n}}{n} \\
& \sum X=\frac{\sum X_{n}}{n}
\end{aligned}
$$

Keterangan

$\mathrm{X}_{\mathrm{n}}=$ jumlah total bobot nilai

$\mathrm{n}=$ total responden

\section{Analisis Deskriptif Kualitatif}

Data dan informasi yang didapatkan dari hasil pengamatan dan wawancara menggunakan lembar kuisioner dianalisis dengan metode deskriptif kualitatif. Analisis deskriptif kualitatif menangkap hal - hal yang terjadi secara aktual terjadi sebagai subjek penelitian. 
Tabel 2. Pembobotan Kriteria Alat Tangkap Ramah Lingkungan

\begin{tabular}{|c|c|c|c|}
\hline No & Kriteria & Penjelasan & Bobot \\
\hline 1 & Memiliki selektivitas yang tingi & $\begin{array}{l}\text { - Alat menangkap lebih dari tiga spesies dengan } \\
\text { ukuran yang berbeda jauh } \\
\text { - Alat menangkap tiga spesies dengan ukuran } \\
\text { yang berbeda jauh } \\
\text { - Alat menangkap kurang dari tiga spesies } \\
\text { dengan ukuran yang kurang lebih sama } \\
\text { - Alat menangkap satu spesies saja dengan } \\
\text { ukuran yang kurang lebih sama }\end{array}$ & 4 \\
\hline 2 & $\begin{array}{l}\text { Tidak merusak habitat, tempat } \\
\text { tinggal dan berkembang biak } \\
\text { organisme }\end{array}$ & $\begin{array}{l}\text { Menyebabkan kerusakan habitat pada wilayah } \\
\text { yang luas } \\
\text { Menyebabkan kerusakan habitat pada wilayah } \\
\text { yang sempit } \\
\text { - } \quad \text { Menyebabkan kerusakan sebagian habitat pada } \\
\text { wilayah yang sempit } \\
\text { - Aman bagi habitat (tidak merusak habitat) }\end{array}$ & $\begin{array}{l}3 \\
4\end{array}$ \\
\hline 3 & $\begin{array}{l}\text { Menghasilkan ikan yang } \\
\text { bermutu baik }\end{array}$ & $\begin{array}{ll}\text { - } & \text { Ikan mati dan busuk } \\
\text { - } & \text { Ikan mati, segar dan cacat } \\
\text { - } & \text { Ikan mati segar } \\
\text { - } & \text { Ikan hidup }\end{array}$ & $\begin{array}{l}1 \\
2 \\
3 \\
4\end{array}$ \\
\hline 4 & $\begin{array}{l}\text { Hasil tangkapan yang terbuang } \\
\text { minimum }\end{array}$ & 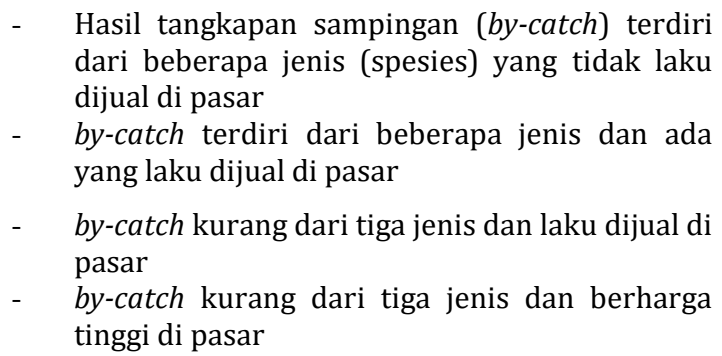 & 4 \\
\hline 5 & $\begin{array}{l}\text { Alat tangkap yang digunakan } \\
\text { harus memberikan dampak } \\
\text { minimum terhadap } \\
\text { biodiversitas }\end{array}$ & $\begin{array}{l}\text { - Alat tangkap dan operasinya menyebabkan } \\
\text { kematian semua makhluk hidup dan merusak } \\
\text { habitat } \\
\text { Alat tangkap dan operasinya menyebabkan } \\
\text { kematian beberapa spesies dan merusak } \\
\text { habitat } \\
\text { Alat tangkap dan operasinya menyebabkan } \\
\text { kematian beberapa spesies tetapi tidak } \\
\text { merusak habitat } \\
\text { - Aman bagi keanekaan sumberdaya hayati }\end{array}$ & 4 \\
\hline 6 & $\begin{array}{l}\text { Diterima secara sosial } \\
\text { 1. Biaya investasi murah } \\
\text { 2. Menguntungkan secara } \\
\text { ekonomis } \\
\text { 3. Tidak bertentangan dengan } \\
\text { budaya setempat } \\
\text { 4. Tidak bertentangan dengan } \\
\text { peraturan yang ada }\end{array}$ & $\begin{array}{l}\text { - Alat tangkap memenuhi satu dari empat butir } \\
\text { pernyataan di atas } \\
\text { - } \quad \text { lat tangkap memenuhi dua dari empat butir } \\
\text { pernyataan di atas } \\
\text { - Alat tangkap memenuhi tiga dari empat butir } \\
\text { pernyataan di atas } \\
\text { - Alat tangkap memenuhi semua butir } \\
\text { pernyataan diatas }\end{array}$ & 3 \\
\hline
\end{tabular}

Sumber: Departemen Kelautan dan Perikanan (2006)

Tabel 3. Kategori Alat Tangkap Ramah Lingkungan

\begin{tabular}{ccl} 
No & Rentang Nilai & \multicolumn{1}{c}{ Kategori } \\
1 & $1-9$ & Sangat tidak ramah lingkungan \\
2 & $10-18$ & Tidak ramah lingkungan \\
3 & $19-27$ & Ramah lingkungan \\
4 & $28-36$ & Sangat ramah lingkungan \\
\hline
\end{tabular}

Sumber: Departemen Kelautan dan Perikanan (2006) 


\section{HASIL DAN PEMBAHASAN}

Hasil tangkapan nelayan yang didaratkan di tempat pendaratan ikan tradisional Pulau Alai selama penelitian, didapatkan 7 jenis ikan. Hasil tangkapan utama terdapat 4 jenis ikan, yaitu ikan lome (Harpodon nehereus), ikan bulu ayam (Coilia sp.), ikan biang (Setipinna sp.), dan ikan timah (Trichiurus sp.). Sedangkan hasil tangkapan sampingan terdapat 3 jenis ikan, yaitu ikan diles atau ikan gelik (Otolithoides sp.), ikan baji - baji (Grammoplites scaber), dan ikan sebelah (Cynoglossus sp.). Gambar dan klasifikasi ikan hasil tangkapan utama dan sampingan dapat dilihat pada Tabel 4.

Tabel 4. Gambar dan klasifikasi ikan hasil tangkapan utama dan sampingan di Pulau Alai

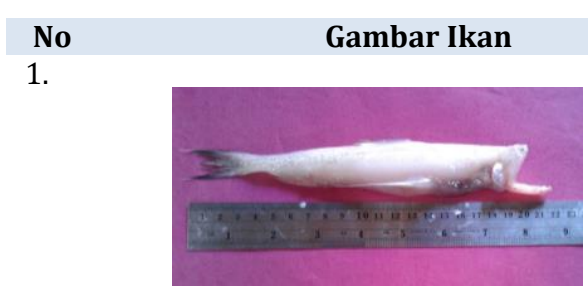

2.

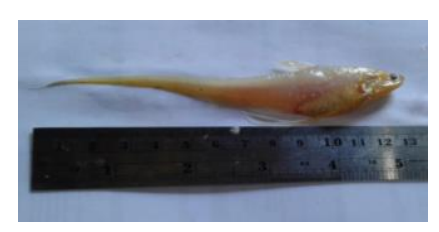

3.

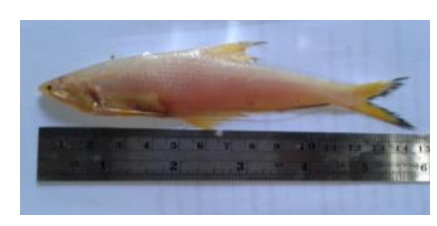

4.

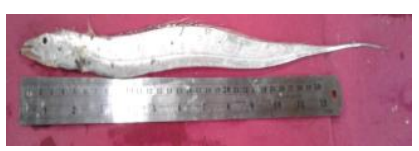

5.

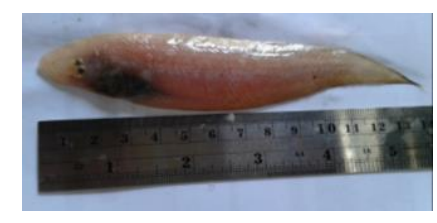

6.

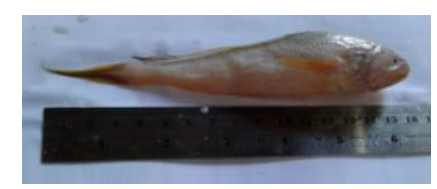

\section{Klasifikasi}

\begin{tabular}{|c|c|}
\hline Nama & : Ikan Lome \\
\hline Kingdom & : Animalia \\
\hline Filum & : Chordata \\
\hline Kelas & : Actinopterygii \\
\hline Ordo & : Aulopiformes \\
\hline Family & : Synodontidae \\
\hline Genus & : Harpodon \\
\hline Spesies & : Harpodon nehereus \\
\hline Nama & : Ikan Bulu Ayam \\
\hline Kingdom & : Animalia \\
\hline Filum & : Chordata \\
\hline Kelas & : Actinopterygii \\
\hline Ordo & : Clupeiformes \\
\hline Family & : Clupeidae \\
\hline Genus & : Coilia \\
\hline Spesies & : Coilia sp. \\
\hline Nama & : Ikan Biang \\
\hline Kingdom & : Animalia \\
\hline Filum & : Chordata \\
\hline Kelas & : Actinopterygii \\
\hline Ordo & : Clupeiformes \\
\hline Family & : Engraulidae \\
\hline Genus & : Setipinna \\
\hline Spesies & : Setipinna sp. \\
\hline Nama & : Ikan Timah \\
\hline Kingdom & : Animalia \\
\hline Filum & : Chordata \\
\hline Kelas & : Actinopterygii \\
\hline Ordo & : Perciformes \\
\hline Family & : Trichiuridae \\
\hline Genus & : Trichiurus \\
\hline Spesies & : Trichiurus sp. \\
\hline Nama & : Ikan Sebelah \\
\hline Kingdom & : Animalia \\
\hline Filum & : Chordata \\
\hline Kelas & : Teleostei \\
\hline Ordo & : Pleuronectiformes \\
\hline Family & : Cynoglossidae \\
\hline Genus & : Cynoglossus \\
\hline Spesies & : Cynoglossus sp. \\
\hline Nama & : Ikan Diles/Ikan Gelik \\
\hline Kingdom & : Animalia \\
\hline Filum & : Chordata \\
\hline Kelas & : Actinopterygii \\
\hline Ordo & : Perciformes \\
\hline Family & : Scianidae \\
\hline Genus & : Otolithoides \\
\hline Spesies & : Otolithoides sp. \\
\hline
\end{tabular}


7.

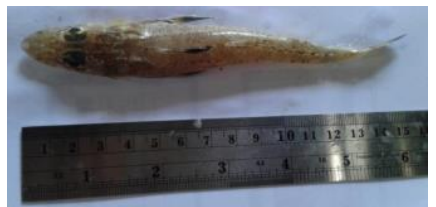

Nama : Ikan Baji - baji

Kingdom : Animalia

Filum : Chordata

Kelas : Actinopterygii

Ordo : Scorpaniformes

Family : Platycephalidae

Genus : Grammoplites

Spesies : Grammoplites scaber

Sumber : Data Primer (2018)

Komposisi hasil tangkapan utama dan sampingan jaring di Pulau Alai disajikan pada Tabel 5.

Tabel 5. Komposisi hasil tangkapan utama dan sampingan yang didaratkan di Pulau Alai

\begin{tabular}{clcc}
\multirow{2}{*}{ No } & & Nama Ikan & \multicolumn{2}{c}{ Jumlah Produksi (kg/hari) } \\
& & TPI I & TPI II \\
\hline 1 & Ikan Lome & 7,52 & 6,98 \\
2 & Ikan Bulu Ayam & 1,84 & 1,84 \\
3 & Ikan Biang & 3,32 & 3,5 \\
4 & Ikan Timah & 1,88 & 1,48 \\
5 & Ikan Diles atau Ikan Gelik & 1,02 & 0,96 \\
6 & Ikan Baji - Baji & 0,45 & 0,42 \\
7 & Ikan Sebelah & 0,74 & 0,54 \\
8 & Lainnya & 2,7 & 2,6 \\
& Total & $\mathbf{1 9 , 4 7}$ & $\mathbf{1 8 , 3 2}$ \\
\hline
\end{tabular}

Persentase komposisi hasil tangkapan utama dan sampingan ikan di tempat pendaratan ikan Pulau Alai disajikan pada Gambar 2. Grafik distribusi frekuensi ukuran panjang ikan di Pulau Alai disajikan pada Gambar 3.

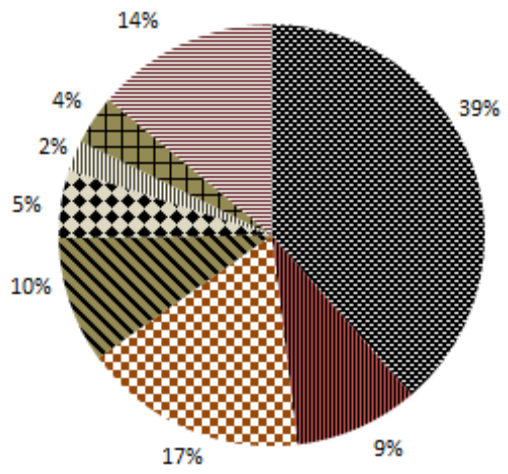

(a)

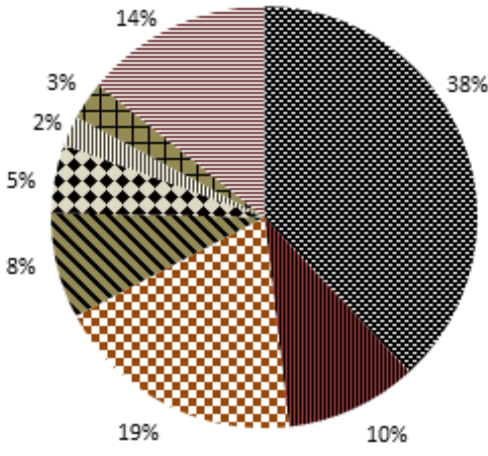

(b)
Ikan Lome
III Ikan B ulu Ayam
'Ikan Biang
s Ikan Timah
- Ikan Diles atau Ikan Gelik IIII Ikan B aji - Baji
tr Ikan Sebelah
$\equiv$ Lainnya

Gambar 2. Persentase komposisi hasil tangkapan utama dan sampingan yang didaratkan Pulau Alai (a) TPI I (b) TPI II 


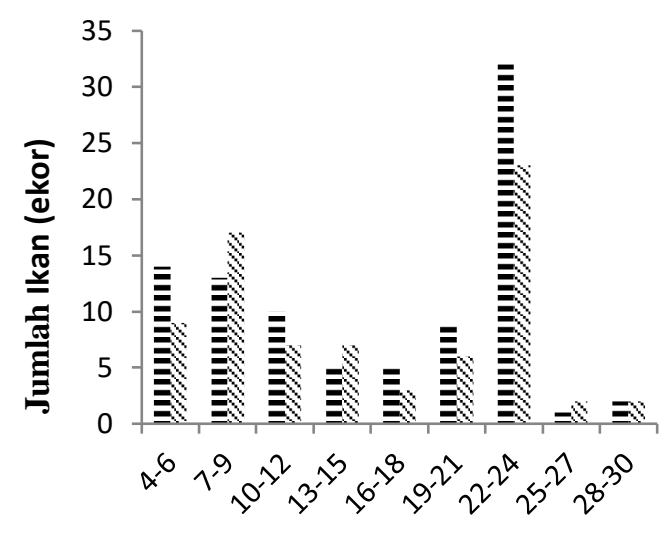

Ukuran panjang ikan (cm)

(a)

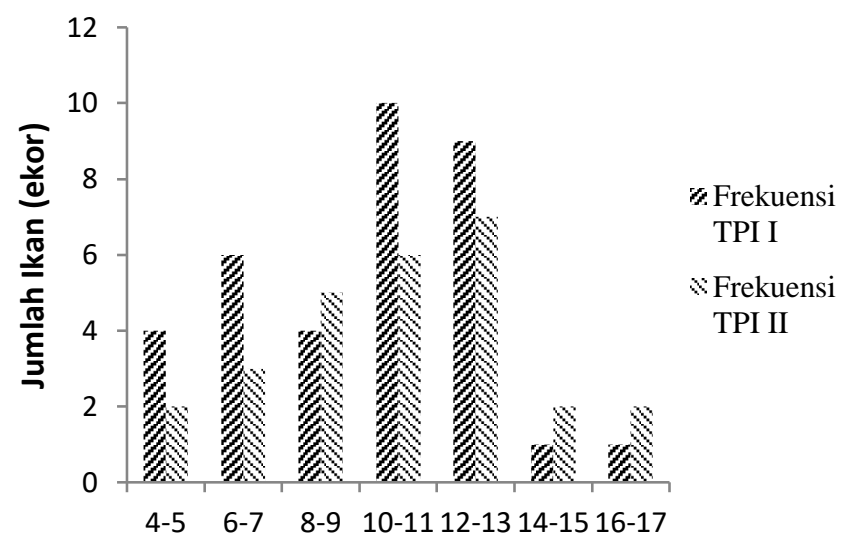

Ukuran panjang ikan $(\mathrm{cm})$

(c)

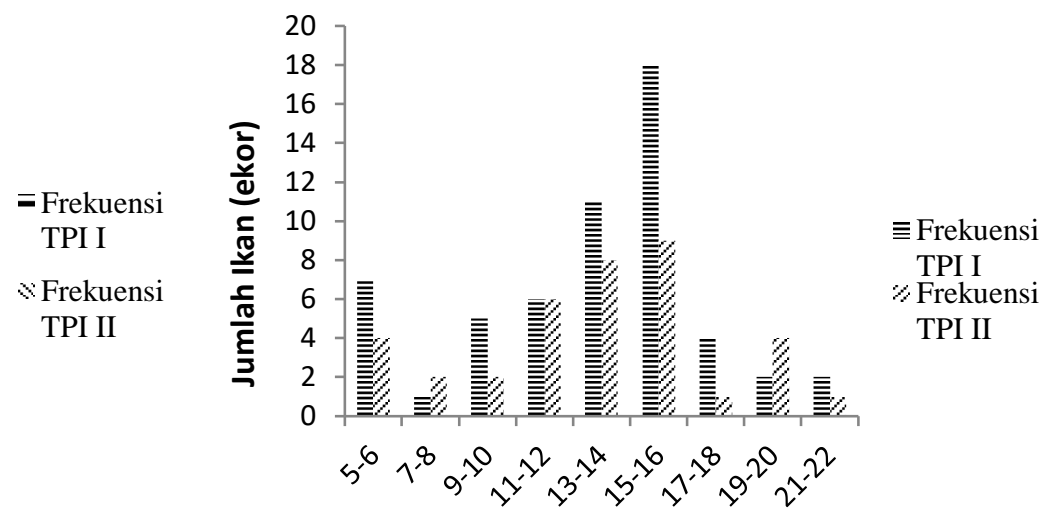

Ukuran panjang ikan $(\mathrm{cm})$

(b)

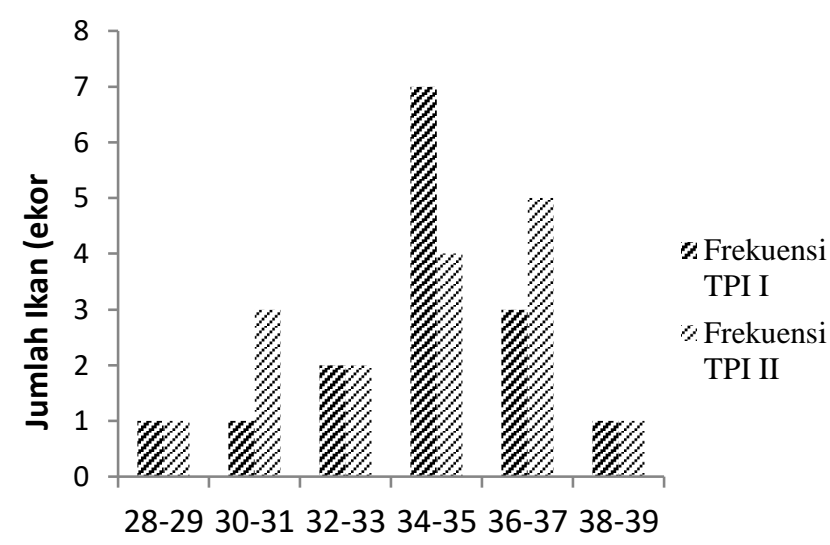

Ukuran panjang ikan $(\mathrm{cm})$

(d)

Gambar 3. Distribusi Frekuensi Ukuran Panjang Ikan Hasil Tangkapan Utama (a) Lome, (b) Biang, (c) Bulu Ayam, (d) Timah

Menurut penelitian Firdaus et al. (2013) ukuran ikan lome layak tangkap di perairan Juata Kota Tarakan oleh nelayan berkisar antara ukuran kurang lebih 35,068 cm sampai ukuran maksimal 35,743 cm, sedangkan ikan lome hasil tangkapan nelayan di Pulau Alai memiliki ukuran maksimum antara 25-28 cm. Perbedaan ukuran ikan hasil tangkapan dapat dipengaruhi karena perbedaan tempat penangkapan ikan dan waktu penangkapan ikan sesuai dengan pernyataan Mulfizar et al. (2012) bahwa perbedaan daerah penangkapan akan memiliki perbedaan kelebihan ketersediaan makanan atau rendahnya kepadatan predator. Selain ketersediaan pakan atau pemangsa, faktor biotik, abiotik dan manajemen perikanan juga dapat mempengaruhi ukuran ikan pada suatu perairan (Putra et al., 2018).

Menurut nelayan di Pulau Alai, ikan biang hanya ditemukan dalam jaring nelayan pada bulan - bulan tertentu. Hal ini sesuai dengan penelitian yang dilakukan oleh Herlan di perairan estuari Selat Panjang, bahwa jumlah hasil tangkapan pada bulan pengamatan terlihat adanya perubahan, yaitu hasil tangkapan pada bulan Mei paling banyak sedangkan pada bulan Juli tidak didapatkan ikan biang. Perbedaan ini diduga ikan biang pada bulan Mei beruaya ke perairan estuari untuk mencari makan sehingga tertangkap ke jaring nelayan Pulai Alai yang cenderung melakukan penangkapan di daerah penangkapan yang dekat dengan mangrove, sedangkan pada bulan Juli beruaya ke perairan laut untuk melakukan pemijahan. Ikan biang hidup pada perairan laut dan payau (Herlan, 2013).

Berdasarkan hasil riset Rupawan et al. (2011) di perairan estuari sungai Indragiri menunjukkan bahwa ikan bulu ayam jantan pertama kali matang gonad pada ukuran $9,8 \mathrm{~cm}$, sedangkan pada ikan betina pertama kali matang gonad pada ukuran $8,2 \mathrm{~cm}$. Berdasarkan penelitian tersebut, menunjukkan bahwa ikan bulu ayam yang tertangkap di Pulau Alai memiliki kondisi yang baik karena ukuran yang tertangkap sudah melebihi ukuran ikan pertama kali matang gonad. Selain itu, ikan bulu ayam bersifat oceanodromus yaitu melakukan pemijahan di laut, sedangkan alat tangkap jaring yang digunakan nelayan Pulau Alai pada saat penangkapan dioperasikan di sekitaran pantai dan mangrove. Dari informasi tersebut maka dapat diduga bahwa lokasi penangkapan bukan merupakan area pemijahan bagi ikan bulu ayam.

Ukuran maksimum ikan timah yang tertangkap di Pulau alai mencapai ukuran $38-39 \mathrm{~cm}$. Ukuran ini lebih kecil dibandingkan hasil penelitian tangkapan ikan timah di perairan Palabuhan ratu dengan panjang maksimal mencapai 99,7 cm (Ernawati \& Butet, 2012) dan kabupaten Bantul (Novianingrum et al., 2017). Ukuran spesies ikan pada suatu perairan dapat dipengaruhi oleh jenis alat tangkap yang digunakan. Nelayan di perairan Palabuhan ratu, umumnya menggunakan alat tangkap pancing, yaitu pancing rawai dan pancing ulur nomor 6, 7, 8, dan 9, dan alat tangkap yang 
digunakan di perairan Kabupaten Bantul adalah jaring insang dengan ukuran mata jaring 1,75 dan 2 inci, sedangkan di Pulau Alai menggunakan alat tangkap jaring dengan ukuran mata jaring $2-2,5 \mathrm{~cm}$. Hasil skoring selektivitas alat tangkap jaring di Pulau Alai disajikan pada Tabel 6.

Tabel 6. Hasil Skoring Selektivitas Alat Tangkap Jaring

\begin{tabular}{|c|c|c|c|c|c|c|}
\hline \multirow{2}{*}{ No } & \multirow{2}{*}{ Kriteria } & \multirow{2}{*}{$\begin{array}{c}\text { Total } \\
\text { Responden }\end{array}$} & \multicolumn{4}{|c|}{ Jumlah responden*Skor } \\
\hline & & & 1 & 2 & 3 & 4 \\
\hline 1 & Memiliki selektivitas yang tinggi & 36 & 36 & 0 & 0 & 0 \\
\hline 2 & $\begin{array}{l}\text { Tidak merusak habitat, tempat tinggal } \\
\text { dan berkembang biak organisme }\end{array}$ & 36 & 0 & 0 & 105 & 4 \\
\hline 3 & Menghasilkan ikan yang bermutu baik & 36 & 2 & 0 & 102 & 0 \\
\hline 4 & $\begin{array}{l}\text { Hasil tangkapan yang terbuang minimum } \\
\text { Alat tangkap yang digunakan harus }\end{array}$ & 36 & 2 & 68 & 0 & 0 \\
\hline 5 & $\begin{array}{l}\text { memberikan dampak minimum terhadap } \\
\text { biodiversitas }\end{array}$ & 36 & 0 & 0 & 60 & 64 \\
\hline \multirow[t]{3}{*}{6} & Diterima secara sosial & 36 & 3 & 10 & 75 & 12 \\
\hline & Total Skor & & 43 & 78 & 342 & 80 \\
\hline & $\begin{array}{l}\text { Penjumlahan Total Skor } \\
\text { Penjumlahan Total Skor/Total } \\
\text { Responden }\end{array}$ & & $\begin{array}{c}543 \\
\mathbf{1 5 , 0 8}\end{array}$ & & & \\
\hline
\end{tabular}

Sumber : Data Primer hasil survei dan wawancara (2018)

Berdasarkan Tabel 6., hasil skoring selektivitas alat tangkapa jaring di Pulau Alai menunjukkan bahwa alat tangkapa jaring tidak memiliki memiliki selektivitas yang tinggi karena alat tangkap menangkap lebih dari tiga jenis spesies dengan ukuran yang berbeda jauh. Berdasarkan penelitian Andriani et al. (2015) di Kabupaten Asahan, alat tangkap jaring yang ramah lingkungan dan selektif seharusnya memiliki nilai skor 3, yaitu memiliki selektivitas ukuran dan selektivitas jenis yang diuraikan bahwa alat tangkap menangkap kurang dari tiga spesies dengan ukuran yang kurang lebih sama. Pengoperasian alat tangkap jaring di Pulau Alai menyebabkan kerusakan sebagian habitat pada wilayah yang sempit. Pengoperasian alat tangkap jaring di Pulau Alai berpengaruh terhadap habitat karena pengoperasiannya tidak jauh dari pantai atau daerah sekitaran mangrove. Alat tangkap jaring agar memenuhi persyaratan diterima secara sosial lebih banyak masyarakat nelayan yang memilih tiga dari empat butir pernyataan, yaitu biaya investasi murah, menguntungkan secara ekonomis, dan tidak bertentangan dengan budaya setempat. Modal yang digunakan untuk alat tangkap tergolong cukup murah, karena ada sebagian nelayan yang merajut sendiri alat tangkap jaring tersebut. Penggunaan alat tangkap jaring di Pulau Alai juga tidak bertentangan dengan budaya setempat karena banyak masyarakat yang menggunakan alat tangkap jaring tersebut. Menurut masyarakat Pulau Alai, belum ada peraturan terkait penggunaan alat tangkap jaring.

Masyarakat Pulau Alai dalam melakukan kegiatan penangkapan ikan, alat tangkap yang digunakan adalah jaring dengan mesh size antara $2-2,5 \mathrm{~cm}$. Armada penangkapan yang digunakan masih tergolong sederhana yaitu perahu dayung, sehingga jangkauan daerah penangkapan ikan tidak jauh. Penentuan daerah penangkapan ikan (fishing ground) yang diterapkan nelayan untuk menangkap ikan biasanya dilakukan berdasarkan informasi atau pengalaman hasil tangkapan sebelumnya. Jika pada daerah penangkapan sebelumnya mendapatkan hasil tangkapan yang banyak maka daerah penangkapan tetap berada di daerah sebelumnya. Aktivitas penangkapan nelayan yang ada di Pulau Alai dipengaruhi oleh musim di saat akan melakukan penangkapan. Pada musim angin bertiup dari arah Utara angin sangat kencang dan laut berombak besar, sehingga mereka tidak turun untuk melaut. Biasanya nelayan akan turun melaut pada saat musim Timur, karena angin bertiup pelan dan laut relatif tidak berombak. Ada juga musim Selatan meskipun angin agak kencang dan laut relatif berombak nelayan masih bisa juga melaut. Ada juga musim Barat keadaan angin relatif tidak stabil sehingga terkadang mereka harus turun melaut dan bahkan tidak bisa sama sekali. Pengolahan hasil tangkapan ikan di Pulau Alai masih sederhana dan skala kecil, yaitu pengolahan ikan asin dan serunding lome.

\section{SIMPULAN}

Ikan yang ditemukan di tempat pendaratan ikan I dan II Pulau Alai didapatkan 7 jenis ikan. Hasil tangkapan utama terdapat 4 jenis ikan, yaitu ikan lome (Harpodon nehereus), ikan bulu ayam (Coilia sp.), ikan biang (Setipinna sp.), ikan timah (Trichiurus sp), sedangkan hasil tangkapan sampingan terdapat 3 jenis ikan, yaitu ikan ikan diles atau ikan gelik (Otolithoides sp.), ikan baji - baji (Grammoplites scaber), dan ikan sebelah (Cynoglossus sp.).

Pola pemanfaatan perikanan di Pulau Alai masih cenderung sederhana dalam hal penggunaan alat tangkap, kapal penangkapan ikan serta pengetahuan mengenai musim penangkapan, daerah penangkapan dan pengolahan perikanan yang masih tradisional. Alat tangkap jaring yang digunakan masyarakat nelayan Pulau Alai tidak memiliki nilai selektivitas yang tinggi. 


\section{UCAPAN TERIMA KASIH}

Penulis menyampaikan ucapan terima kasih kepada semua pihak yang turut membantu dalam penelitian, terutama kepada orang tua, nelayan dan perangkat desa di Pulau Alai beserta dosen pembimbing.

\section{REFERENSI}

Andriani, H., Brown, A., \& Rengi., P. (2015). Studi Teknologi Alat Tangkap Jaring Sembilang yang Menggunakan Tuasan di Desa Pematang sei Baru Kecamatan Tanjung Balai Asahan. Jurnal Kelautan dan Perikanan. 20(1) : 32-42.

Badan Pusat Statistik Daerah Kabupaten Karimun [BPS Kabupaten Karimun]. (2015). Statistik Daerah Kecamatan Ungar 2015. Badan Pusat Statistik Kabupaten Karimun Provinsi Kepulauan Riau. Karimun.

Departemen Kelautan dan Perikanan. (2006). Panduan Jenis-jenis Penangkap Ikan Ramah Lingkungan. Bina Marina Nusantara. Jakarta.

Ernawati, Y., \& Butet, N.A. (2012). Studi biologi reproduksi ikan layur (Superfamili Trichiuroidea) di Perairan Palabuhanratu, Kabupaten Suka-bumi, Jawa Barat. Bionatura-Jurnal Ilmu-ilmu Hayatidan Fisik, 14(3) : 211-218.

FAO. (1995). Food Agriculture Organization. Code of Conduct for Responsible Fisheries. FAO Fisheries Departement.

Firdaus, M., Salim, G., Maradhy, E., Abdiani, I.M., \& Syahrun. (2013). Analisis Pertumbuhan dan Struktur Umur Ikan Nomei (Harpodon nehereus) di Perairan Juata Kota Tarakan. Jurnal Akuatika, 4(2) : 159-173.

Herlan. 2013. Beberapa Aspek Biologi Ikan Biang (Setipinna sp) di Perairan Estuari Selat Panjang Riau. Fisheries, 2(1) : 1-4.

Mulfizar., Zainal, A., Muchlisin., \& Dewiyanti, I. (2012). Hubungan panjang berat dan Faktor Kondisi Tiga Jenis Ikan yang Tertangkap di Perairan Kuala Gigieng, Aceh Besar Provinsi Aceh. Jurnal Depik, 1(1) : 1-9.

Novianingrum, P., Djumanto., Murwantoko., \& Setyobudi, E. (2017). Reproductive biology of largehead hairtails, Trichiurus lepturus Linnaeus, 1758 in the coastal area of Bantul Regency. Jurnal Iktiologi Indonesia, 17(2) : 227-238.

Putra, R.D., Suryanti, A., Kurniawan, D., Pratomo, A., Irawan, H., Raza'I, T.S., Kurniawan, R., \& Pratama, G. (2018). Responses of Herbivorous Fishes on Coral Reef Cover in Outer Island Indonesia (Study Case: Natuna Island). E3S Web of Conferences, 47: 04009.

Rupawan., Asyari., Herlan., Hukmanan, A., Wulandari, T. N. M., Suryaningrat, S., Saiyani, A., Abidin, M., \& Ardiansyah. (2011). Kajian Stok dan Bioekologi Sumberdaya Ikan di Perairan Estuari Sungai Indragiri Riau. Laptekris Estuari Sungai Indragiri. Provinsi Riau.

Saanin, H. (1986). Taksonomi dan Kunci Identifikasi Ikan 2. Bina Cipta. Bogor.

Sima, A.M., Yunasfi., \& Zulham, A.H. (2013). Identifikasi Alat Tangkap Ikan Ramah Lingkungan Di Desa Bagan Asahan Kecamatan Tanjung Balai. Repository Universitas Sumatera Utara.

Susiana \& Rochmady. (2018). Pendugaan stok cumi-cumi Loligo sp. di Perairan Kabupaten Pangkajene dan Kepulauan, Sulawesi Selatan, Indonesia. Jurnal Pengelolaan Perairan, 1(1): 14-30

White, W.T., Last, P.L., Dharmadi., Faizah, R., Chodrijah, U., Iakandar, B.P., Pogonoski, J. J., Puckridge, M., \& Blaber, S.J.M. (2013). Market Fishes of Indonesia. Australian Centre for International Agricultural Research. Australian Government. 